\title{
COLLABORATION THEORY AND COMMUNITY TOURISM PLANNING
}

\author{
Tazim B. Jamal \\ Donald Getz \\ University of Calgary, Canada
}

\begin{abstract}
This paper applies the theoretical constructs of collaboration to tourism destinations and offers insight into interorganizational collaboration for one specific tourism domain, the planning and development of local, community-based tourism destinations. Drawing primarily from the literature on interorganizational relations, the theoretical constructs of collaboration are discussed first. Challenges and considerations in the planning and development of local tourist destinations are then summarized, followed by examples of community-based collaboration research. Propositions are presented for guiding collaborative initiatives and for investigating the application of collaboration theory to the planning and development of tourism destinations, from a community-involvement perspective. Keywords: Collaboration; community-based tourism planning, stakeholders, propositions.
\end{abstract}

Résumé: L'article applique les constructions théoriques de la collaboration aux destinations touristiques et jette de la lumière sur la collaboration interorganisationnelle pour un domaine particulier du tourisme: la planification et le développement communautaire des destinations touristiques locales. On discute d'abord les constructions théoriques de la collaboration en faisant appel à la littérature sur les relations interorganisationnelles. On résume les défis et les considérations de la planification et du développement des destinations touristiques locales, et on donne ensuite des exemples de recherches sur la collaboration communautaire. On présente des suggestions pour guider des initiatives collaboratives et pour investiguer l'application de la théorie de la collaboration à la planification et au développement des destinations touristiques dans un contexte communautaire. Mots-clés: collaboration, planification touristique communautaire, dépositaires d'enjeux, propositions.

\section{INTRODUCTION}

The lack of coordination and cohesion within the highly fragmented tourism industry is a well-known problem to destination planners and managers. Gunn (1988) stated that continuous tourism planning must be integrated with all other planning for social and economic development, and could be modeled as an interactive system. He pointed out that "the 'go-it-alone' policies of many tourism sectors of the past are giving way to stronger cooperation and collaboration. ... No one business or government establishment can operate in isolation" (Gunn 1988:272). Inskeep (1991) has also pointed out the importance of an effective organizational structure for tourism management and the

Tazim Jamal is a Ph.D. student in Tourism and Hospitality Management at the University of Calgary (Calgary, Alberta, Canada T2N 1N4. E-mail: "tbjamal@acs.ucalgary.ca"). Her main area of study is tourism policy and planning, with special interest in cross-sectoral collaborative processes and tourism in developing countries. Donald Getz is Professor of Tourism and Hospitality Management at the University of Calgary. He specializes in tourism planning, impact assessment, and event tourism. 
need for continuous, integrated planning. Achieving coordination among the government agencies, between the public and the private sector, and among private enterprises is a challenging task, however, and requires the development of new mechanisms and processes for incorporating the diverse elements of the tourism system.

Although the terms cooperation and collaboration are frequently used in the tourism planning and policy literature (Stevens 1988; Teye 1988; Zins 1987), little effort has been made to distinguish between these two concepts or to draw from interorganizational studies on collaboration within the fields of organizational behavior, theory, and development. In a general sense, "cooperation" means "working together to some end" (Fowler and Fowler 1964:269), but does not contain the complex interpretations and the necessary conditions covered by the term collaboration. While interorganizational collaboration is receiving widespread attention in several research disciplines, the potential application of this emerging body of knowledge for managing the complex and dynamic tourism domain has not been clearly addressed. A notable exception is the study by Selin and Beason (1991), which applied interorganizational relations to the study of cooperative relations between the US Forest Service, chambers of commerce, and tourism associations adjacent to an Arkansas National Forest. From their study, the authors suggested that "tourism managers must adopt a more domain-level focus and consider the interdependencies among organizations when making decisions" (Selin and Beason 1991:649). More recently, Selin (1993) outlined trends in tourism towards collaborative actions, as well as incentives and constraints to collaboration among tourism organizations. The application of collaboration theory specifically to community-based tourism planning has not been reported as yet, despite its potential usefulness to destination planning and management.

The primary aim of this article is to discuss some of the key theoretical constructs of collaboration and to demonstrate their relevance to community-based tourism planning. It is argued that a domain-level focus in community tourism planning is critical due to the interdependencies among multiple stakeholders in a community tourism destination. It is further argued that collaboration offers a dynamic, processbased mechanism for resolving planning issues and coordinating tourism development at the local level. Though the discussion focuses on the community level, it should be noted that similar arguments can be forwarded for the application of collaboration to regional level tourism planning and development.

\section{COLLABORATION AND COMMUNITY DESTINATIONS}

\section{Collaboration Theory}

As described in a seminal work by Gray (1989), collaboration can be used effectively to resolve conflict or advance shared visions, where stakeholders recognize the potential advantages of working together. Here, collaboration is "a process of joint decision making among key stakeholders of a problem domain about the future of that domain" (Gray 1989:227). More recent debate on the nature of collaboration 
has given rise to other definitions and interpretations (Roberts and Bradley 1991; Wood and Gray 1991). In light of the conflicting interpretations associated with collaboration, a working definition has been developed in this article for collaboration in community-based tourism planning and development domains. Based on an examination of the literature and adapting Gray's (1989) definition, the authors posit that collaboration for community-based tourism planning is a process of joint decisionmaking among autonomous, key stakeholders of an inter-organizational, community tourism domain to resolve planning problems of the domain and/or to manage issues related to the planning and development of the domain. As used in this definition and throughout this paper, the term community refers to a "body of people living in the same locality," as defined by the concise Oxford dictionary. A community-based tourism destination may be viewed by adopting an ecosystem approach, where visitors interact with local living (hosts, services) and non-living (landscape, sunshine) to experience a tourism product (Murphy 1985). Stakeholders are the actors with an interest in a common problem or issue and include all individuals, groups, or organizations "directly influenced by the actions others take to solve a problem" (Gray 1989:5). Though decisions are made jointly on a consensus basis, these stakeholders are autonomous since they retain their independent decision-making powers while abiding by shared rules within the collaborative alliance (Wood and Gray 1991). The problem domain refers to a situation where the problems are complex and require an inter- or multi-organizational response, since they are beyond the capability of any single individual or group to solve single-handedly (Trist 1983).

Critical to the understanding of collaboration is the concept of the inter-organizational domain. Astley (1984) pointed out that the field of business policy has primarily characterized organization-environment relationships in terms of constraints, choice, and competition; even when the unit of analysis shifts from the firm to the population level, the managerial focus has tended to move from devising business and corporate strategy to analyzing and selecting strategies to compete within the constraints of the overall industry. Missing was the recognition of increasing interconnectedness of the organizational environments and thereby the need for collective, collaborative responses to cope with the resulting turbulence (Astley 1984). The notion of the turbulent environment dates back to the seminal work of Emery and Trist (1965:22) on the causal texture of organizational environments (i.e., the area of interdependencies that belong within the environment itself). Those authors identified four different causal textures, of which the first two are placid environments and the third a disturbed-reactive environment (comparable to the economists oligopolic market, characterized by the existence of a number of similar organizations). New to the literature is the fourth texture, turbulent fields, whose dynamic properties arise from the interaction of the component organizations and from the field itself. In a turbulent field, competing organizations, all acting independently in many diverse directions, "produce unanticipated and dissonant consequences in the overall environment which they share," where dissonances increase as the field becomes more densely occupied, producing the impression that "the ground" is in motion (Trist 1983:273). 
Hence, uncertainty is higher in this fourth type of environment than in the disturbed-reactive field. The technocratic bureaucracies that typify the type 3 environment show diminishing adaptability in the face of increasing environmental complexity, change, and interdependence, seeming to increase turbulence levels by strategies that have become inappropriate (Trist 1977a). Essentially, when faced with complex problems that are beyond the capabilities of any one organization to solve singlehandedly, the strategic management process needs to incorporate the perspective of inter-organizational domains. This is the "functional social systems that occupy a position in social space between the society as a whole and the single organization" (Trist 1983:270). Resolving societal level issues under conditions of interdependence, complexity, and uncertainty then involves developing collaborative strategies that optimize the payoffs to stakeholders in the domain and reduce the turbulence in the field (Trist 1977b). As suggested by Trist, a negotiated order will need to be founded on collaboration, which is the "value base appropriate for the adaptive cultivation of interdependence" (1983:273).

\section{The Collaboration Process}

Gray outlines five key characteristics of the collaboration process: the stakeholders are independent; solutions emerge by dealing constructively with differences; joint ownership of decisions is involved; the stakeholders assume collective responsibility for the ongoing direction of the domain; and collaboration is an emergent process, where collaborative initiatives can be understood as "emergent organizational arrangements through which organizations collectively cope with the growing complexity of their environments" (1989:236). Gray, based on McCann 1983, proposes a three-stage model through which collaboration develops. The first stage consists of problem-setting (identifying key stakeholders and issues), and is followed by the second stage of direction-setting (identifying and sharing future collaborative interpretations; appreciating a sense of common purpose). The third stage is implementation (institutionalizing the shared meanings that emerge as the domain develops), which may or may not be required, depending on the nature and objective of the collaboration. Drawing from the body of literature on interorganizational collaboration, conditions and steps for facilitating each stage of a community-based tourism collaboration are advanced in Figure 1.

The study of interorganizational relationships has traditionally followed two streams: one, the exchange perspective (Levine and White 1961), where relations form when members of two or more organizations perceive mutual benefits or gains from interacting and, two, the resource dependency approach (Pfeffer and Salancik 1978), where organizations form relationships in order to gain or improve control over scarce resources in the environment. As proposed by Schmidt and Kochan (1977), however, organizations are not likely to engage in only symmetrical exchange relationships or only power-dependency relationships, but would likely have a mixture of each type. Furthermore, it has been suggested that, in addition to competitive or market forces, collaboration can be stimulated or inhibited by institutional 


\begin{tabular}{|c|c|c|}
\hline $\begin{array}{l}\text { Stages and } \\
\text { Propositions }\end{array}$ & Facilitating Conditions & Actions/Steps \\
\hline $\begin{array}{l}\text { Stage I. } \\
\text { Problem-Setting } \\
\text { Propositions } \\
\text { applicable: } \\
\text { P1, P2, P3, P4, P5 }\end{array}$ & $\begin{array}{l}>\text { Recognition of interdependence } \\
>\text { identification of a required number } \\
\text { of stakeholders } \\
>\text { perceptions of legitimacy among } \\
\text { stakeholders } \\
>\text { legitimate/skilled convener } \\
>\text { positive beliefs about outcomes } \\
>\text { shared access power } \\
>\text { mandate (external or internal) } \\
>\text { adequate resources to convene and } \\
\text { enable collaboration process. }\end{array}$ & $\begin{aligned} &> \text { Define purpose and domain } \\
&> \text { identify convener } \\
&> \text { convene stakeholders } \\
&> \text { define problems/issues to resolve } \\
&>\text { identify and legitimize stakeholders } \\
&>\text { build commitment to collaborate by } \\
& \text { raising awareness of } \\
& \text { interdependence } \\
&>\text { balancing power differences } \\
&>\text { addressing stakeholder concerns } \\
&>\text { ensuring adequate resources } \\
& \text { available to allow collaboration to } \\
& \text { proceed with key stakeholders } \\
& \text { present. }\end{aligned}$ \\
\hline $\begin{array}{l}\text { Stage II: } \\
\text { Direction-Setting } \\
\text { Propositions } \\
\text { applicable: } \\
\text { P1, P2, P3, P6 }\end{array}$ & $\begin{array}{l}\text { Coincidence of values } \\
>\text { dispersion of power among } \\
\text { stakeholders. }\end{array}$ & $\begin{array}{l}\text { Collect and share information } \\
>\text { appreciate shared values, enhance } \\
\text { perceived interdependence } \\
>\text { ensure power distributed among } \\
\text { several stakeholders } \\
>\text { establish rules and agenda for } \\
\text { direction setting } \\
>\text { organize subgroups if required } \\
>\text { list alternatives } \\
>\text { discuss various options } \\
>\text { select appropriate solutions } \\
>\text { arrive at shared vision or } \\
\text { plan/strategy through consensus. }\end{array}$ \\
\hline $\begin{array}{l}\text { Stage III: } \\
\text { Implementation } \\
\text { Propositions } \\
\text { applicable: } \\
\text { P1, P2, P6 }\end{array}$ & $\begin{array}{l}\text { High degree of ongoing } \\
\text { interdependence } \\
>\text { external mandates } \\
>\text { redistribution of power } \\
>\text { influencing the contextual } \\
\text { environment. }\end{array}$ & $\begin{array}{l}\text { Discuss means of implementing and } \\
\text { monitoring solutions, shared vision, } \\
\text { plan or strategy } \\
>\text { select suitable structure for } \\
\text { institutionalizing process } \\
>\text { assign goals and tasks } \\
>\text { monitor ongoing progress and } \\
\text { ensure compliance to collaboration } \\
\text { decisions. }\end{array}$ \\
\hline
\end{tabular}

Figure 1. A Collaboration Process for Community-Based Tourism Planning Facilitating conditions and actions/steps based on Gray $(1985,1989)$.

forces, such as legal action and social norms, which drive organizations to adapt in order to facilitate legitimization by institutional actors (Sharfman, Gray, and Yan 1991). These issues of legitimacy and power become critical considerations in the selection of stakeholders for an interorganizational collaboration, for they influence every stage of the collaboration process (Figure 1).

As suggested by Gray and Hay (1986), a legitimate stakeholder possesses some degree of power over the domain. Their study of the National Coal Policy Project (NCPP), a collaborative change effort between environmental groups and firms involved in the mining and consumption of coal, is instructive in demonstrating that power imbalances and legitimacy issues related to the stakeholders can inhibit both 
the initiation and the success of a collaboration. The exclusion of key stakeholders from the start of the NCPP collaboration (in order to facilitate consensus building) resulted in inhibiting the implementation of the collaboration's recommendations, since it restricted perceptions of the project's legitimacy as a policy forming instrument. This issue of legitimacy of participating stakeholders is a critical one in tourism planning, where collaborative possibilities are complicated by the existence of diverse organizations and other publics who often hold widely different viewpoints and strong vested interests. Difficulties in achieving a collaborative solution are directly related to the differences in value orientation between the stakeholders (Brown 1991; Gray 1989). Hence Gray (1985) recommended the use of a mediator to assist in solving disputes over legitimacy, and the use of a convener to guide proceedings.

\section{Changing Organizational Forms}

Turbulence in the global environment of the $90 \mathrm{~s}$ is driving the need to develop collaborative coping mechanisms different from the hierarchically structured forms of the traditional organization. Austrom and Lad proposed problem-solving networks as an umbrella term to encompass the innovative organizational forms evolving to solve complex social issues; these are "issues-oriented collaborative entities which focus on complex social issues not adequately addressed by traditional institutions" (1986:311). Trist suggested that there are two broad classes of domains, which are complementary: ones that display some kind of centering in terms of referent organizations and those that stay uncentered and retain a network character. He further argued that while such networks can be important in providing "environmental probes into possible futures," purposeful action and turbulence reduction in the domain may be better undertaken by a referent organization. This is a self-regulating, collaborative body that could form consciously or unconsciously to collaborate on domain related issues and may have several functions: regulation, appreciation of trends and issues, providing leadership and direction, and infrastructure support (Trist 1977a, 1983).

Brown (1991:5) discussed four kinds of bridging organizations, which span the social gaps among organizations and constituencies to enable coordinated actions. They range from loosely structured networks to formally structured partnerships or coalitions. Westley and Vredenburg (1991) discussed collaborative forms as a function of two critical dimensions: degree of domain organization and degree of motivation to collaborate. Problem domains are underorganized when the boundaries of the domain are unclear, shifting, or in dispute, with the degree of domain-related awareness frequently low or nonexistent (Brown 1980 in Gray and Hay 1986). Based on a case study of interorganizational collaboration between environmental groups and a retail grocery chain (Loblaws, Inc.), Westley and Vredenburg (1991) suggested that the sustainable development domain is underorganized and strategic bridging (a distinctive form of third-party intervention in collaboration) 
may be suitable in the early stages of domain organization, until further domain organization occurs.

In the authors' observation, collaborative forms in tourism destination planning and management are a relatively new and emerging field of study. Organizational forms most suited to destination planning and development have to be identified and studied in much further detail than has occurred to date.

\section{Collaboration Studies in Tourism}

Trist (1979) has argued that the greatest leverage for change lies in the groups and temporary systems arising from networks, because individuals are changing faster than organizations and the values likely to beneficially shape the future are emerging in individuals. To illustrate this point, Trist described case studies of four innovative, voluntary organizations in separate community-geographic domains that developed from the grass-roots level to address specific domain issues. One of these was the Craigmillar Festival Society (CFS), which arose spontaneously in the early 60s, within a low-income area of Edinburgh, the United Kingdom. In addition to sustaining various arts efforts, the CFS has grown into an all-encompassing community development organization, typifying a self-regulating referent organization through which sustained transformation of the domain can occur (Trist 1979, 1983).

Several examples of public-private cooperative efforts and participation by community members in local tourism planning and destination management are present in the tourism literature (Gill and Williams 1994; McGinnis 1992; Oaks 1992; Ritchie 1993). These studies reflect the necessity of involving key stakeholders and refining processes for joint decision-making on destination planning and management issues within a community-based domain. A case study by Getz and Jamal (1994) in the rapidly growing mountain destination of Canmore, Alberta (Canada) noted clearly that collaborative change efforts were being attempted at various sublevels within the overall tourism planning and development domain, for example, among local environmental groups, between municipalities, and through a grass roots, nonprofit resident organization. An innovative exercise in the popular destination of Greater Victoria, British Columbia (Canada) described by Murphy (1988) also demonstrated interesting collaborative properties. In the early to mid-80s, about 53 agencies and groups were involved with the tourism industry of Greater Victoria. In order to solve the logistical and marketing difficulties being faced by this fragmented domain, a 2-day workshop was convened, which was attended by about 150 people, representative of the various agencies and groups. At the top of the prioritized issues that emerged during the workshop was the need to develop a secretariat structure allowing broad-based community input into tourism marketing for Greater Victoria and an umbrella organization to develop a long-term, community-based marketing strategy. A "blueprint committee" was then struck to develop the tasks and structure of the new marketing organization, which essentially replaced the existing convention and visitors bureau. 
The need for domain level consensus is further substantiated by Selin and Beason's study on interorganizational relations between the US Forest Service, chambers of commerce, and tourism associations adjacent to an Arkansas National Forest. Results supported the hypothesis that domain consensus is positively related to the degree of cooperative relations occurring between tourism organizations, and showed that lack of awareness and differing ideologies act as barriers to effective communication between natural resource management agencies and tourism advocacy organizations. From a tourism planning perspective, the study suggested that community-level interorganizational relationships should be examined empirically since it is the logical level at which tourism planning should occur (Selin and Beason 1991). Interorganizational collaboration theory offers strong possibilities for managing tourism and recreation related issues at the destination level, since destination community domains generally encompass multiple, interdependent stakeholders who could hold divergent views on tourism development.

\section{The Nature of Community Tourism Destinations}

A destination community's assets and resources, such as its infrastructure and recreational facilities, can be shared by its inhabitants, visitors, public, and private sector interests. Tourism development then takes on the characteristics of a public and social good whose benefit may be shared by the numerous stakeholders in the local destination. A public good, by its very nature, is a candidate for government activity, since "the benefits from a public or social good, unlike those from a purely private good, are seen to involve external consumption effects on more than one individual" (Samuelson and Scott 1975:144). Hence, destination residents may be less willing to support additional tourism development through local revenue tax funds (Long, Perdue and Allen 1990) and could favor government control over development (Allen, Hafer, Long and Perdue 1993). The local authorities have the delicate task of juggling private sector interests with local resident needs and wants, in order to maintain the economic health of the community and ensure that development is sustainable. Government involvement in the development of tourism infrastructure often needs to be supplemented by external private capital for superstructure development (facilities and amenities) at the destination. The influx of external developers, financiers, entrepreneurs, and others to provide these additional services and goods increases the number of actors and the complexity of the tourism domain, since the stakeholder values and perspectives on tourism development may vary widely. External forces that impact on the community domain as well as flow of resources and tourists into and out of the permeable domain boundaries also influence the destination's stakeholders. The destination domain is thus characterized by an "open-system" of interdependent, multiple stakeholders, where the actions of one stakeholder impact on the rest of the actors in the community. Furthermore, no single organization or individual can exert direct control over the destination's development process. 


\section{Diverse Community Views}

Research on resident attitudes indicates that residents' opinions on tourism development within a community can vary greatly. For example, several studies have shown that people who benefit from tourism perceive greater economic but lesser social or environmental impact from tourism than those who do not (Lankford and Howard 1994; Milman and Pizam 1988; Pizam 1978; Prentice 1993). Some studies on rural communities have demonstrated predominantly positive perceptions of tourism development's impact on the local economy (Allen et al 1993). However, research by Long et al (1990) on 28 rural Colorado communities indicated that residents' favor of tourism development increased initially, but became less favorable after a threshold level of development was reached. As well, longitudinal study by Getz (1994) showed that resident support for tourism was linked to perceptions of benefits outweighing the costs of tourism development; this supported Ap's (1992) contention that social exchange theory can help explain resident attitudes. Furthermore, resident perceptions of social and economic benefits may be influenced by the amount of tourism education of the residents (Brayley, Var and Sheldon 1990), while lack of familiarity with development proposals may have an overall adverse effect on general resident attitudes towards tourism projects (Keogh 1990). Other resident studies have indicated that community involvement in planning and development is critical to the overall sustainability of tourism in the destination (Cook 1982; Murphy 1985). Since resident perceptions and opinions on tourism development may be influenced significantly by changing variables, such as the scale (and nature) of tourism development and related employment opportunities, it can be inferred from these various studies that community participation has to take a form which is dynamic and active, in order to enable tourism planning and development to be adjusted as the economic, social and environmental perceptions change within the community.

As advocated by several researchers (Gunn 1988; Haywood 1988; Inskeep 1991; Murphy 1983), representatives from the various stakeholder groups should be involved at an early stage in the planning process. Gray also refers to the importance of involving all the relevant and legitimate key actors at an early stage during collaborative decision-making, since "failure to include them in the design stage only invites technical or political difficulties during implementation" (1989: 65). According to Gray (1985), a legitimate stakeholder is one who has the right and capacity to participate in the process; a stakeholder who is impacted by the actions of other stakeholders has a right to become involved in order to moderate those impacts, but must also have the resources and skills (capacity) in order to participate. Legitimacy is an important issue, for the community should be reasonably reassured that the stakeholders assembled are capable of representing their interests (Blank 1989). Additionally, several researchers have advocated joint decision-making by key stakeholders and consensus in this process as important notions for attaining economically and socially appropriate tourism development (Cook 1982; Haywood 1988; Ritchie 
1988). Passive instruments, such as mail surveys, are appropriate for gathering resident attitudes and perceptions towards tourism development and planning, but active participation and joint decision-making by key representative stakeholders may be essential in the strategic planning process to yield useful results.

The development of dynamic and collaborative planning processes is especially crucial in those destination communities that are experiencing strong growth and change due to tourism. In such domains, diverse community attitudes toward tourism development and growth raise concern that community-driven tourism planning may be an unachievable ideal. However, as suggested by Prentice (1993), division of opinion on development benefits may present an opportunity or a weakness. The opportunity is that issue development strategies can be formulated if divisions can be pre-identified, but the weakness is that the differences may not be resolvable without dissension. The case study of Canmore (Getz and Jamal 1994) concluded that, despite the controversial history of planning and development in the town and the diverse stakeholders present, there was a recognition of interdependency and that coming to a consensus on the type and scale of tourism development might not be as difficult as it appeared. Murphy's (1983) discriminant analysis of three decision-making groups (business sector, administration, and residents) in major tourism centers in the United Kingdom showed that there were significant differences in perceptions and attitudes towards local tourism development. Nonetheless, the study showed that the groups were sufficiently close in overall community interests, suggesting that trade-offs and compromises in future tourism planning may be achievable (Murphy 1983).

\section{Facilitating Community Tourism Collaboration}

A set of six propositions is advanced below as a guide to managers, planners, and researchers studying collaboration in the domain of tourism planning and destination management. They relate to the key conditions facilitating tourism planning collaborations at the community level (Figure 1), with each proposition considered an essential facilitator for one or more of the three stages in the collaboration process. These six propositions can also be construed as a starting point for further proposition development, based on the many facilitating conditions and actions described in Figure 1. The propositions are based on the premise that this domain is a turbulent one, where conflict over planning and development exists or where mechanisms for sharing ideas and developing directions are required. Cross-sectoral collaboration for destination planning among key stakeholders should help to reduce turbulence in the domain and increase the likelihood of sustainable tourism development. Collaboration offers a dynamic and flexible process for incorporating the often diverse views of multiple and interdependent stakeholders, such that changes can be made to the planning process as situations evolve. In environmentally and culturally sensitive destinations, this is a valuable aid for incorporating the results of cumulative impact studies and of changing political and social conditions. Furthermore, these propositions apply to those com- 
munity tourism planning domains which, while characterized by the presence of numerous organizations, lack a well-defined interorganizational process and represent underorganized systems. As defined by Brown (1980), an underorganized system contains potential networks of organizations instead of established networks or other collaborative structures.

Proposition 1: Collaboration for community-based tourism planning will require recognition of a high degree of interdependence in planning and managing the domain. Perceptions of interdependence may be enhanced by emphasizing the following aspects of interdependence in community tourism domains: sharing limited community amenities and resources (environmental, infra- and superstructure, recreational facilities, hospitality etc.); potential negative impacts of tourism development on the sociocultural and natural environment which, in turn, could affect the economic viability of the tourism industry in the community; fragmentation of the tourism industry and inability of one sector to effectively operate alone since a critical mass of attractions, facilities, amenities is required.

A destination community has to ensure the presence of a requisite mass of attractions, suitable accommodation, and adequate transportation to be able to satisfy tourists. Facilities such as health services, entertainment, and restaurants are required, in addition to the hospitality and courtesy of the local residents. Tourism development that exceeds the carrying capacity of the economic, natural, and sociocultural environment will impact negatively on the overall tourism industry of the community, due to the close interrelations of the elements within the community's tourism system. Hence, the stakeholders within the tourism planning domain should be aware of the high degree of interdependence with each other and with the natural environment. This could increase their motivation to engage in collaboration, for "the recognition by stakeholders that their desired outcomes are inextricably linked to actions of other stakeholders is the fundamental basis for collaborating" (Gray 1989:58).

Proposition 2: Collaboration will require recognition of individual and/or mutual benefits to be derived from the process. The mutual benefits include more effective and efficient tourism development (thereby improving the destination's competitive advantage); greater degree of environmental and sociocultural sustainability; and avoidance of conflict. Individual benefits will be observed in: more effective representation for some groups; more resources for some groups to influence the planning domain; reduced uncertainty in a private firm's environment, thereby improving the firm's decision making and potential for success; more effective public sector management of scarce resources; and greater individual resident satisfaction.

Waddock (1989) proposed that three conditions must be present for organizations to participate in collaborative efforts: recognition of interdependence, perceptions that significant benefit will result from the collaboration, and recognition of importance of the issue(s). Logsdon (1991), however, argued that an organization needs to begin to consider only two essential factors before joining a collaborative effort for social problem solving: the interest or stake of the organization in the outcome, and its perceived interdependence with other groups in dealing with the social problem. In a tourism planning collaboration, perception of benefits to be derived from a collaboration may be a 
more important precondition than recognition of the importance of the issue. An organization may recognize the importance of an issue, but might perceive that self-interest is best served by utilizing a more familiar or known strategy than collaborating. Or it may decide that the issue is important, but not as important to the organization's operations as other issues which require priority attention. Environmental groups may join a collaboration due to the importance of the planning issues to long-term environmental sustainability and heritage preservation (potential mutual benefits). Some private firms may be more motivated by immediate self-interest, although environmental and social pressure are creating a greater awareness in firms to develop a social conscience. However, the parties might be able to recognize that adversarial arrangements, including tribunals and courts, could serve to alienate special interests in the destination community, potentially leading to costly and less than optimal settlements.

Special interest groups (e.g., environmental and resident organizations), which are often comprised primarily of volunteer members, may find it particularly beneficial to join a collaboration, because effort has to be made to ensure that the key stakeholders have adequate resources to participate in the process. As suggested by Gray (1985), some stakeholders may require incentives to induce participation, which offset their perceptions that collaborating may reduce their access to scarce resources. For various community and environmental groups, increased power to influence decision-making and additional resources to enable participation are potential benefits to encourage participation.

Proposition 3: Collaboration for community-based tourism planning will require a perception that decisions arrived at will be implemented (i.e., the process has legitimacy and power to either make or strongly influence the planning decisions). In the tourism planning domain, the collaboration's legitimacy and power will stem from: inclusion of key stakeholders; external mandate, or perception of a clear internal mandate (general objectives, purpose); and presence of adequate resources to carry out the process and implement outcomes.

Limited time and other resources, as well as skepticism by groups that have been involved in conflict over tourism development, may tend to make potential participants wary about joining, unless they perceive that the collaboration's decisions will be implemented. This issue of the power and authority to be vested in the collaboration is a difficult one that may need to be addressed at an early stage in the collaborative planning process. It may constitute a strong precondition for collaboration in the community tourism domain, where fragmented and independent planning decisions by the numerous tourism-related organizations are conducive to power struggles over resources. Therefore, some stakeholders, such as large resort operators, may feel threatened by a potential loss of control over decision-making and resources, while others, such as small environmental and residents groups, may feel that the collaboration will not empower them to be able to influence decision-making over the tourism domain's future. In light of the fragmentation in the tourism domain, an external mandate by a regional or state authority may sometimes be necessary to initiate collaboration at the community level. Conversely, a clear delineation of 
the potential collaboration's purpose by a legitimate convener may be adequate to motivate participation. However, as proposed by Gray (1985), mandate alone is not sufficient to generate conditions conducive to collaboration; other conditions, such as recognition of interdependence are essential. Additionally, there should be a perception that adequate resources in the form of expertise, time, and money are present in order to ensure that the collaboration will not be interrupted due to lack of resources.

Proposition 4: Collaboration for tourism destination planning will depend on encompassing the following key stakeholder groups: local government plus other public organizations having a direct bearing on resource allocation; tourism industry associations and sectors such as Chamber of Commerce, Convention and Visitor Bureau, and regional tourist authority; resident organizations (community groups); social agencies (e.g., school boards, hospitals); and special interest groups.

In addition to the benefits already outlined, collaboration for tourism planning and development at the community level can also be cost-efficient, if key stakeholders can be selected to represent the generally numerous and diverse viewpoints in the domain. These would include representatives from the local community and others from outside the geographic locale of the community who may be legitimate stakeholders in this domain. Representative community views in a collaboration should reduce the need for costly and time-consuming referendums and surveys by local planners. Additionally, ineffective "token" resident participation may be avoided through active resident representation in the collaboration. Findings by Lankford and Howard, using a multiple-item tourism impact attitude scale to measure resident attitudes towards tourism development in the popular Columbia River Gorge destination (Washington and Oregon in the United States) suggested that "if residents, even long-term natives, feel they can exercise some control over the development process, much of their apprehension regarding tourism development may be reduced" (1994: 134). Determining the specific mix of key stakeholders is a critical task, particularly since adequate resident representation has to be ensured.

The nature of tourism as a public and social good lends strong support to the need for local government involvement in collaborative destination planning and development. The presence of community service organizations, such as school boards, health and social welfare associations, and business representatives, including the local chamber of commerce is clearly necessary. These are important components of the interrelated community tourism system. In addition to the necessary representation of the local tourism organization, it may be necessary to include key actors from the regional planning and marketing levels in order to ensure coordinated planning and to minimize the gap between the marketing and planning of tourism destinations.

Proposition 5: A convener is required to initiate and facilitate communitybased tourism collaboration. The convener should have the following characteristics: legitimacy, expertise, resources, plus authority, and may be derived from a government agency, an industry firm, or group such as the local Chamber of Commerce, or the local tourist organization (e.g., convention and visitors bureau). According to Gray (1989), the role and identity of the convener is 
a critical component in the problem-setting phase, which essentially represents the pre-negotiation phase. The role of the convener is to identify and bring all legitimate stakeholders to the table. Convening power (i.e., the ability to induce stakeholders to participate), may come from "holding a formal office, from a long-standing reputation of trust with several stakeholders, or from experience or reputation as an unbiased expert on the problem" (Gray 1989:71). In the destination community domain, the local government exercises authority over land-use within municipal boundaries and is also responsible for the well-being and satisfaction of its constituents. Therefore, this local authority might be able to perform the role of the convener, particularly if assisted by a local or higher level mandate (e.g., from the regional or provincial level government). Local government as a convener could be particularly suitable when the issues revolve around directing the community's future growth and development, or resolving a land-use development problem.

Alternatively, the collaboration might be convened by a powerful business or special interest group. A conflict over a major resort development proposal, for example, may incite the developer to convene the collaboration in order to resolve the problems which impact directly on the project. Conversely, a more general problem, such as limiting the pace of tourism development, may cause a local business association to initiate a collaboration on behalf of its members, in order to arrive at a level of tourism development which could satisfy everyone.

Proposition 6: An effective community collaboration process for strategic tourism planning for the destination requires: formulation of a vision statement on desired tourism development and growth; joint formulation of tourism goals and objectives; self-regulation of the planning and development domain through the establishment of a collaborative (referent) organization to assist with ongoing adjustment of these strategies through monitoring and revisions.

Since planning requires a time horizon, planning by a public authority within a community can become very difficult due to changes caused by elections. This lends further support to the need to involve residents and other key stakeholders into a flexible and dynamic planning process that can sustain the changing administration and adjust to other forces impacting on the tourism system. Woodley's (1993) study of tourism development in the community of Baker Lake showed that the government documents emphasized community involvement, but extensive community consultation occurred only on an individual project basis, with no overall vision of the community's future and no consultation on the cumulative impacts of developing numerous individual facilities. Hence, one of the critical research questions is: where in the overall destination planning process is stakeholder collaboration most effective? For example, should the stakeholders be involved in the visioning process only, or also in the formation of tourism goals and policies? Should local authorities be left with the responsibility of formulating and implementing goals and policies, once a community vision has been established through a community-based collaboration? Or should a referent organization be formed for ongoing monitoring and adjustment of the community's tourism plans? Local tourist organizations, such as convention and visitors bureaus, generally have mul- 
tiple stakeholders and a mandate focused on the marketing and promotion requirements of the destination. For the planning needs of the domain, however, it may become necessary to form a new structure if an existing one cannot be adapted to suit the collaborative task. Discussing peripheral tourism destinations, Keller suggested that success in maintaining local control and a sustainable, development pace would depend on "a functioning and powerful peripheral tourism organization" which "would require the support of all sectors of the peripheral tourism industry. ..." (1987:27).

It can be argued, therefore, that in the fragmented tourism domain, perceived interdependence and key stakeholder involvement are not adequate for achieving success; methods must be devised for finding common grounds for facilitating consensus and for implementing the collaboration's results (if required). A community collaboration initiated to develop a formal community vision, for example, could result in a vision document that becomes ratified by the local council. A community-based tourism collaboration might thus proceed along the stages and steps outlined in Figure 1.

\section{CONCLUSIONS}

The strategic planning of tourism destinations is a complex task due to the interdependence of multiple stakeholders and fragmented control over the destination's resources. This paper outlines some of the characteristics of community-based tourism destinations and suggests that collaboration, as a dynamic process-oriented strategy, may be suitable to manage turbulent planning domains at the local level. This process might also be suitable for coordinating regional-level planning of tourism resources and destinations. In addition to aiding publicprivate sector interactions, collaboration may provide an effective mechanism for community involvement in tourism planning, through selection of key stakeholders to represent the various public interests. In light of the increasing pace of change and intensifying competition resulting from the globalization of trade, business and travel, the need to find new ways for destination communities to be competitive and yet retain a sense of place is critical. Sustainable tourism development at a local and global level will therefore require much greater cooperation and collaboration than practiced to date. In emerging tourism domains, it may be necessary to specifically implement a collaborative community-based planning process and form referent organizations to manage the tourism development affairs of the community and the region.

Planners and managers, however, need to be aware of the potential inhibitors and problems that may arise during collaboration, and implement appropriate actions to resolve them. For example, rather than accumulate and gain control over scarce resources, firms are being asked to share resources (skills, knowledge, etc.) in some ventures and compete in others. The sharing of resources could induce "freeloading," whereby some stakeholders may depend on others in the collaboration to produce necessary benefits. Hence, an organization may be deterred from being in a collaboration due to a perceived risk 
of free-loading participants. Additionally, organizations that are not familiar with collaboration may be reluctant to join, out of fear of losing control over the planning and development domain. They might also feel that the resources they possess could be better utilized by adopting a more familiar strategy, even though that strategy may have produced less than optimal outcomes in the past. Furthermore, municipalities might also perceive risks in collaborating together for tourism planning and destination management, since they too are often involved in competing with each other for scarce funds, and for attracting private investments. Concerns about loss of control over decisionmaking may also prevent local authorities from entering into a collaboration.

Clearly, the facilitators and inhibitors to collaboration in community-based tourism domains need to be identified through empirical research in order to understand the conditions under which collaboration can be used as a process to resolve problems and advance "shared visions." The stages and implementation of the collaboration process need to be investigated, with attention paid to the development of appropriate structures for ongoing management of the planning domain. The ramifications of interdependencies and of the simultaneous use of competitive and collaborative strategies in tourism planning and destination management by organizational stakeholders merit greater examination. Collaboration in tourism planning domains might only be achievable among certain stakeholders groups and within specific decision-making parameters, where the term consensus may take on varied interpretations. Ongoing research through in-depth case studies, both qualitative and quantitative, provides some answers to these crucial issues. Longitudinal research is especially recommended in order to be able to trace the performance of collaborative planning processes and strategies over time. Six propositions have been forwarded in this article to assist researchers in developing theory and testing hypotheses in this area. Additionally, it is hoped that these propositions will be useful as a planning guide for destination managers and community planners. $\square \square$

\section{REFERENCES}

Allen, L. R., H. R. Hafer, P. T. Long, and R. R. Perdue

1993 Rural Residents' Attitudes Toward Recreation and Tourism Development. Ap, J. Journal of Travel Research 21(4):27-33.

1992 Residents Perceptions on Tourism Impacts. Annals of Tourism Research 19: 665-690.

Astley, W. G.

1984 Toward an Appreciation of Collective Strategy. Academy of Management Review 9:526-535.

Austrom, D. R., and L. J. Lad

1986 Problem-solving Networks Towards a Synthesis of Innovative Approaches to Social Issues Management. Academy of Management Best Papers Proceedings, J. P. Pearce II and R. R. Robinson, eds., pp. 311-314. Chicago: Academy of Management.

Blank, U.

1989 The Community Tourism Imperative: The Necessity, the Opportunities, its Potential. State College: Venture Publishing. 
Brayley, R., T. Var, and P. Sheldon

1990 Perceived Influence of Tourism on Social Issues. Annals of Tourism Research $17: 285-289$.

Brown, L. D.

1980 Planned Change in Underorganized Systems. In Systems Theory for Organization Development, T. G. Cummings, ed., pp. New York: Wiley.

1991 Bridging Organizations and Sustainable Development. Human Relations 44: 807-831.

Cook, K.

1982 Guidelines for Socially Appropriate Tourism Development in British Columbia. Journal of Travel Research 21:22-28.

Emery, F., and E. Trist

1965 The Causal Texture of Organizational Environments. Human Relations 18: 21-35.

Fowler, H. W., and F. G. Fowler, eds.

1964 The Concise Oxford Dictionary (5th ed.). Oxford: Oxford University Press.

Getz, D.

1994 Resident Attitudes Towards Tourism: A Longitudinal Case Study in Spey Valley, Scotland. Tourism Management (in press).

Getz, D., and T. Jamal

1994 The Environment-Community Symbiosis: A Case for Collaborative Tourism Planning. Journal of Sustainable Tourism (in press).

Gill, A., and P. Williams

1994 Managing Growth in Mountain Tourism Communities. Tourism Management 15:212-220.

Gray, B.

1985 Conditions facilitating Interorganizational Collaboration. Human Relations 38:911-936.

1989 Collaborating: Finding Common Ground for Multiparty Problems. San Francisco: Jossey-Bass.

Gray, B., and T. M. Hay

1986 Political Limits to Interorganizational Consensus and Change. Journal of Applied Behavioral Science 22:95-112.

Gunn, C. A. 1988 Tourism Planning (2nd ed.). New York: Taylor and Francis.

Haywood, M. 1988 Responsible and Responsive Planning in the Community. Tourism Management 9:105-118.

Inskeep, E.

1991 Tourism Planning: An Integrated and Sustainable Development Approach. New York: Van Nostrand Reinhold.

Keller, C. Peter

1987 Stages of Peripheral Tourism Development -Canada's Northwest Territories. Tourism Management 8:20-32.

Keogh, B.

1990 Public Participation in Community Tourism Planning. Annals of Tourism Research 17:449-465.

Lankford, S. V., and D. R. Howard

1994 Developing a Tourism Impact Attitude Scale. Annals of Tourism Research 21:121-139.

Levine S., and P. E. White

1961 Exchange as a Conceptual Framework for the Study of Interorganizational Relations. Administrative Science Quarterly 5:583-601.

Logsdon, J. M.

1991 Interests and Interdependence in the Formation of Social Problem-Solving Collaborations. Journal of Applied Behavioral Science 27:23-37.

Long, P. T., R. R. Perdue, and L. Allen

1990 Rural Resident Tourism Perceptions and Attitudes By Community Level of Tourism. Journal of Travel Research 28(3):3-9.

McCann, J.

1983 Design Guidelines for Social Problem-Solving Interventions. Journal of Applied Behavioral Science 19:177-189. 
McGinnis, D.

1992 The Changing Image of Jackson Hole, Wyoming. In Mountain Resort Development, Proceedings of the Vail Conference, pp. 126-136. Burnaby: The Simon Fraser University Center for Tourism Policy and Research.

Milman, A., and A. Pizam

1988 Social Impacts of Tourism on Central Florida. Annals of Tourism Research 15:191-204.

Murphy, P. E.

1983 Perceptions and Attitudes of Decision Making Groups in Tourism Centers. Journal of Travel Research 21:8-12.

1985 Tourism: A Community Approach. New York: Methuen.

1988 Community Driven Tourism Planning. Tourism Management 9:96-105.

Oaks, S.

1992 Design and Community Development in the Mountain Resort Community of Vail, Colorado: A Comparative Look at Effects of the Town of Vail Master Plan Hazard Reduction Strategies 1974-1991. In Mountain Resort Development, Proceedings of the Vail Conference, p. 55. Burnaby: The Simon Fraser University Center for Tourism Policy and Research.

Pfeffer, J., and G. Salancik

1978 The External Control of Organizations: A Resource-Dependence Perspective. New York: Harper and Row.

Prentice, $\mathrm{R}$.

1993 Community-driven Tourism Planning and Resident Preferences. Tourism Management 14:218-227.

Pizam, A.

1978 Tourism's Impacts: The Social Costs to the Destination Community as Perceived by its Residents. Journal of Travel Research 16(4):8-12.

Ritchie, J. R. Brent

1988 Consensus Policy Formulation in Tourism: Measuring Resident Views via Survey Research. Tourism Management 9:99-212.

1993 Crafting a Destination Vision: Putting the Concept of Resident Responsive Tourism into Practice. Tourism Management 14:29-38.

Roberts, N. C., and R. T. Bradley

1991 Stakeholder Collaboration and Innovation: A Study of Public Policy Initiation at the State Level. Journal of Applied Behavioral Science 27:209-227.

Samulson, P. A., and A. Scott

1975 Economics. Toronto: McGraw-Hill.

Schmidt, S. M., and T. A. Kochan

1977 Interorganizational Relationships: Patterns and Motivations. Administrative Science Quarterly 22:220-234.

Selin, S.

1993 Collaborative Alliances: New Interorganizational Forms in Tourism. Journal of Travel and Tourism Marketing 2(2-3):217-227.

Selin, S., and K. Beason

1991 Interorganizational Relations in Tourism. Annals of Tourism Research 18: 639-652.

Sharfman, M. P., B. Gray, and A. Yan

1991 The Context of Interorganizational Collaboration in the Garment Industry. Journal of Applied Behavioral Science 27:181-208.

Stevens, B.

1988 Cooperative Activities in Competitive Markets. In Tourism Research: Exploring Boundaries, Travel and Tourism Research Association (TTRA), Montreal, Quebec, Canada, pp. 139-141. Salt Lake City: The University of Utah Bureau of Economic and Business Bureau.

Teye, V.

1988 Prospects for Regional Tourism Cooperation in Africa. Tourism Management 9:221-234.

Trist, E. L.

1977a A Concept of Organizational Ecology. Australian Journal of Management 2: 162-175.

1977b Collaboration in Work Settings: A Personal Perspective. The Journal of Applied Behavioral Sciences 13:268-278. 
1979 New Directions of Hope: Recent Innovations Interconnecting Organizational, Industrial, Community and Personal Development. Regional Studies 13:439451.

1983 Referent Organizations and the Development of Interorganizational Domains. Human Relations 36:247-268.

Waddock, S. A.

1989 Understanding Social Partnerships: An Evolutionary Model of Partnership Organizations. Administration and Society 21:78-100.

Westley, F., and H. Vredenburg

1991 Strategic Bridging: The Collaboration between Environmentalists and Business in the Marketing of Green Products. Journal of Applied Behavioral Science 27:65-90.

Wood, D. J., and B. Gray

1991 Towards a Comprehensive Theory of Collaboration. The Journal of Applied Behavioral Science 27:139-162.

Woodley, A.

1993 Tourism and Sustainable Development: The Community Perspective. In Tourism and Sustainable Development: Monitoring, Planning, Managing, J. G. Nelson, R. Butler and G. Wall, eds., pp. 135-146. Dept. of Geography PublicaZins, $M$. tion Series No. 37, University of Waterloo.

1987 Successful Tourism Projects Through Cooperative Strategic Marketing Planning. In Travel and Tourism: Thrive or Survive? Travel and Tourism Research Association 18th Annual Conference, pp. 151-156. Salt Lake City: The University of Utah Bureau of Economic and Business Research.

Submitted 2 July 1993

Resubmitted 14 March 1994

Resubmitted 16 June 1994

Accepted 14 July 1994

Refereed anonymously

Coordinating Editor: Peter Murphy 